\title{
Exogenous relief-forming processes and phenomena on the territory of the Chechen Republic
}

\author{
Rustam Gakaev* \\ Chechen State University named after A.A.Kadyrov, 364024, st. Sheripova, 32, Grozny, Russia
}

\begin{abstract}
Landslide, also known as landslide, is a geological phenomenon that includes a wide range of ground movements such as rockfalls, deep slope collapse and shallow mudflows. Landslides can occur at sea, on the coast and on land. While gravity is the main driving force behind a landslide, there are other factors that affect the initial stability of the slope. Typically, preconditions create certain subsurface conditions that make the site / slope prone to collapse, while the actual landslide often requires a trigger before being triggered. Landslide studies help identify weak areas, classify hillsides into different categories, and minimize the impact of landslides.
\end{abstract}

\section{Introduction}

Geologists, engineers, and other geoscientists often rely on unique and slightly different definitions of landslides. This variety of definitions reflects the complex nature of the disciplines involved in the study of landslide as a major phenomenon. Statistical approaches aim at exploiting the "functional" relationships that exist between a set of instability factors and the past and present distribution of landslides, usually obtained from a landslide inventory map or landslide catalog. The large number of statistical approaches proposed in the literature almost always use classification methods and provide probabilistic estimates suitable for quantifying hazards. Statistical models can be constructed using different thematic and environmental variables derived from existing maps or by processing images and remote sensing data in different landscapes and environmental conditions, covering a wide range of scales and sizes of the study area. The dependent variable is derived from various types of landslide inventory maps or landslide catalogs and is typically used in a binary structure to express the presence or absence of landslides in each mapping unit, where the terrain mapping unit is a regular or irregular geographic subdivision. divide the study area. The occurrence of landslides also changes the overall landscape or geomorphological conditions. Topography and drainage changes due to these hazards. Landslides can destroy forests and other resources. Landslides will also damage man-made structures such as roads, railways, tunnels and buildings in hilly regions. Landslide studies help identify weak areas, classify hillsides into different

\footnotetext{
* Corresponding author: rustam.geofak@yandex.ru
} 
categories, and minimize the impact of landslides. The bedrock is associated with the rocks of the foundation of the hill. They can be massive or fresh, structurally weak or deformed. All of this can be influenced by tectonic forces emanating from deep within or from a nearby huge structure such as a dam. The next factor is the slope of the hills. Slope is a common factor in landslide. First of all, you should understand the categories of bias. The term slope refers to the angle of inclination of the earth's surface. It varies depending on the geomorphic conditions, bedrock, the nature of the overburden, vegetation and drainage systems. Consider the causes of landslides (see Table 1) [2].

Table 1. Causes of landslides.

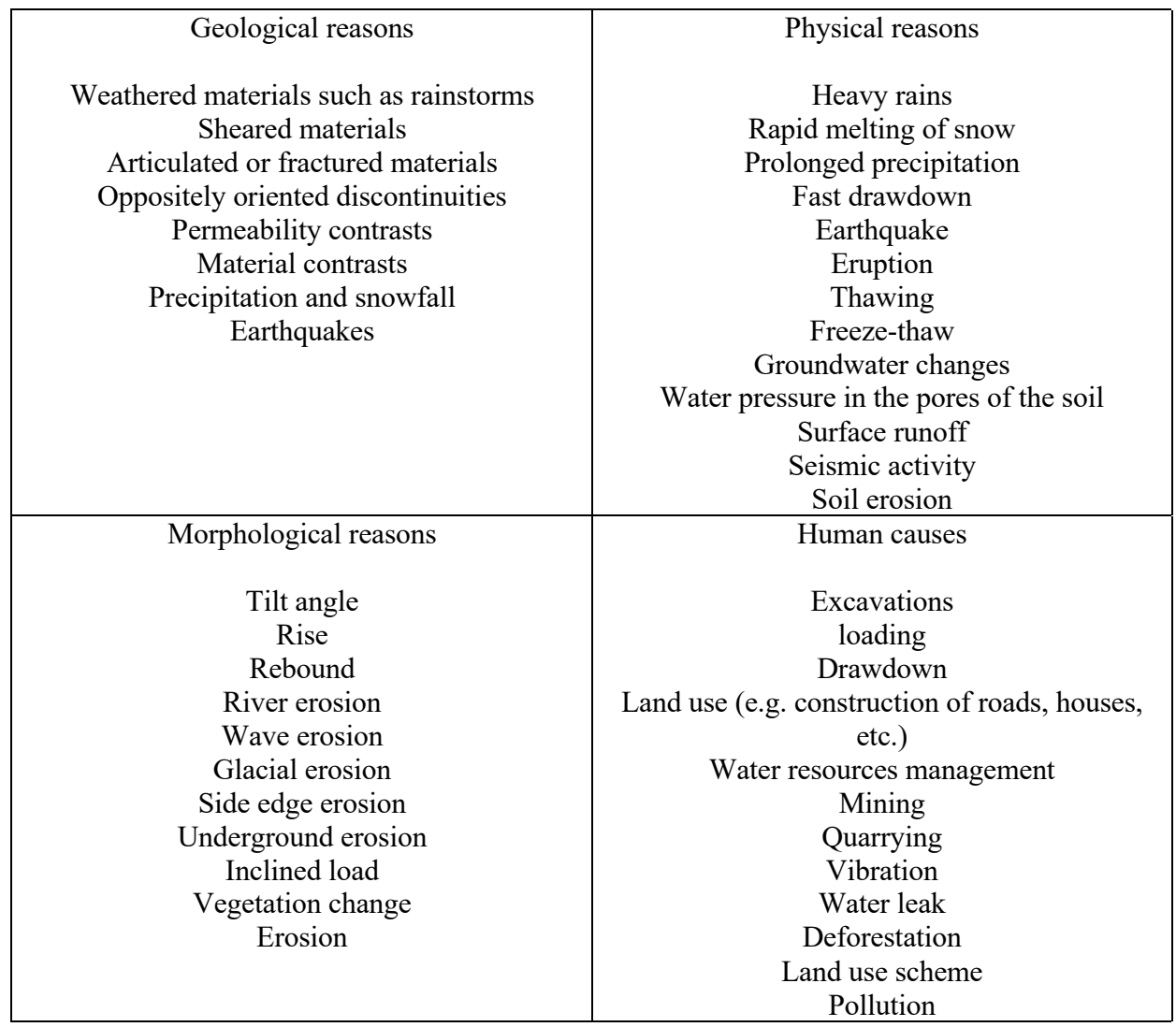

\section{Research methodology}

The development of landslide processes is one of the main natural disasters in the Chechen Republic. It has been established that landslides usually appear in a year or at the beginning of the next year after an unusually high amount of atmospheric precipitation, both in solid and liquid form. In this case, conditions are necessary: maximum saturation with moisture of the soil cover and rocks, while the temperature will be below the average annual, to prevent evaporation 3-4].

The mountainous part, with the greatest activation of landslide processes, is located south of the Chechen foothill plain and is characterized by a highly dissected relief and soft, smooth outlines. The mountain slopes are relatively gentle, the peaks are smoothed. Only in some places is some asymmetry observed in the transverse profile of longitudinal valleys [3]. 
Hills and mountains are typical geomorphological features. They are characterized by gentle or steep slopes. Sometimes they can have sheer steep slopes. They are all called hillsides. The hillsides are typical geomorphological conditions. These are unique climatic zones. They are characterized by thick soil profiles, saturation with soil moisture and plant growth. The hillsides have good rainwater drainage. The bedrock configurations are also very unique. Underground hilly conditions can have two distinct zones: overburden and basement. The overburden may be mostly loose soil, may have a thick weathering zone, adequate natural or artificial vegetation, good root penetration, and all of this is directly influenced by climatic changes, especially precipitation [5].

On the territory of the republic, the occurrence and development of landslides in most cases is associated with Tertiary formations - clay deposits of the Maikop series, the Tortonian and Sarmatian stages. These are, as a rule, finely dispersed, plastic clays with a high content of hydrophilic minerals such as hydromica and montmorillonite. Their distinctive feature is their easy susceptibility to weathering. In the process of weathering, the clays are hydrated, loosened, and their strength is significantly reduced. When moistened, they swell and soak, pass into a plastic state. These properties explain their high predisposition to the development of a landslide process. Almost in all areas of distribution of clayey Tertiary deposits, under appropriate geomorphological conditions (sufficient total energy of the relief, the steepness of the slopes is not less than 5-80, the age of the slopes is not older than the Upper Quaternary), the development of landslides of various sizes, mechanism and age (old and fresh ). These are, first of all, the Black Mountains. The most affected is the eastern part of the Black Mountains - the valleys of the Hulkhulau, Aksai and Yamansu rivers [6]. The Vedensky and Nozhai-Yurtovsky (Benoisky landslide region) administrative districts of Chechnya are characterized by the maximum intensity of landslides in the territory of distribution of Tertiary sediments and in the republic as a whole. The slopes of the Black Mountains in the valley of the Argun River (Shatoisky landslide region) - Shatoevsky region of Chechnya [17] are affected by landslides to a lesser extent.

Earth's natural disasters include earthquakes, tsunamis, volcanic eruptions, cyclones, floods and landslides. Whenever such natural disasters occur, it will lead to serious loss of life and property. Landslides are regular natural disasters that are encountered in hilly and mountainous areas around the world. Landslides have been reported in many countries. Landslide is a general term used to describe the movement of soil, rocks, and organic materials downhill due to gravity, and the landform resulting from such movement. Various classifications of landslides have been proposed in connection with the specific fracture mechanics of slopes, properties and characteristics of the types of fracture [8-9].

In the geomorphological literature, most attempts to predict the occurrence of populations of landslides in a territory are based on the empirical observation that landslides are spatially and temporally discrete events that occur as a result of many interacting, conditioning and triggering factors. Conditioning factors primarily affect where landslides can occur, while trigger factors lead to landslides, that is, at the time or period of occurrence of landslides. Together, conditioning and trigger factors control the extent of the landslide-affected area and the distribution of the size of the cliffs, which is associated with landslide impacts and destructiveness. Due to the complexity and variability of landslide processes, which depend, among other things, on soil, rocks and other characteristics of the landscape, as well as weather or seismic factors, and also because the exact or even approximate location of landslides is unknown before how they arise. In the event of occurrence of individual collapse of slopes in the aggregate of landslides, it can be considered as an implementation of a random process and modeled accordingly [10].

A large number of approaches have been proposed for assessing the "susceptibility" of landslides, which in the geomorphological literature refers to the spatially variable, time- 
independent probability of landslide occurrence in an area, taking into account local terrain conditions. These approaches can be roughly grouped into five main categories, i.e. (i) direct geomorphological mapping, (ii) landslide inventory analysis, (iii) heuristic, indexbased methods, (iv) deterministic, physically based conceptual models, and (v) models statistical forecasting. Each of these approaches has potential benefits and inherent limitations. Geomorphological mapping depends entirely on the skills and experience of the researchers. It can provide reliable results, but is difficult to reproduce, impractical over large areas, and inadequate for quantifying hazard. Inventory analysis depends on the quality and completeness of the landslide maps available. If the inventory is incomplete or incorrect, the susceptibility estimate will be underestimated or biased. Heuristic methods are based on the (often unproven) assumption that all causes of landslides in the area are known and they provide qualitative and subjective predictions that are not suitable for quantitative hazard assessment. Physically based models use the existing understanding of the mechanical laws governing slope instability [11]. Their limitation lies in their inherent simplicity of modeling equations, which may not capture the complex interactions governing slope stability / instability conditions. Moreover, physically based models require large datasets to describe surface and subsurface mechanical and hydrological properties of the terrain, which are difficult and expensive to obtain. As a result, physicsbased models are used primarily for small or very small areas, although there are also several examples of applications for large areas. Finally, statistical approaches aim to exploit the "functional" relationships that exist between the set of instability factors and the past and present distribution of landslides, usually obtained from a landslide inventory map or landslide catalog, almost always use classification methods and provide probabilistic estimates. suitable for quantitative hazard assessment. Statistical models can be constructed using different thematic and environmental variables derived from existing maps or by processing images and remote sensing data in different landscapes and environmental conditions, covering a wide range of scales and sizes of the study area. The dependent variable is derived from various types of landslide inventory maps or landslide catalogs and is typically used in a binary structure to express the presence or absence of landslides in each mapping unit, where the terrain mapping unit is a regular or irregular geographic subdivision. divide the study area. The fitted model is then used to estimate the landslide exposure for each mapping unit [12].

\section{Results and Discussions}

Their limitation lies in their inherent simplicity of modeling equations, which may not capture the complex interactions governing slope stability / instability conditions. Moreover, physically based models require large datasets to describe surface and subsurface mechanical and hydrological properties of the terrain, which are difficult and expensive to obtain. As a result, physics-based models are used mainly for small or very small areas, although there are also several examples of applications for large areas [13]. Finally, statistical approaches aim to exploit the "functional" relationships that exist between the set of instability factors and the past and present distribution of landslides, usually obtained from a landslide inventory map or landslide catalog, almost always use classification methods and provide probabilistic estimates. suitable for quantitative hazard assessment. Statistical models can be constructed using different thematic and environmental variables derived from existing maps or by processing images and remote sensing data in different landscapes and environmental conditions, covering a wide range of scales and sizes of the study area. The dependent variable is derived from various types of landslide inventory maps or landslide catalogs and is typically used in a binary structure to express the presence or absence of landslides in each mapping unit, where the terrain 
mapping unit is a regular or irregular geographic subdivision. divide the study area. The fitted model is then used to estimate the landslide exposure for each mapping unit [14].

A crawl is a sharp downward movement of stone or earth, or both. They come off steep slopes or cliffs. Falling material usually hits the lower slope at an angle less than the angle of fall, causing bouncing. A falling load may break on impact, may roll over steep inclines, and may continue to move until it reaches level ground. They are found all over the world on steep or vertical slopes. They can also be seen in coastal areas and on rocky banks of rivers and streams. The volume of material falling can vary significantly: from individual stones or lumps of earth to massive blocks of thousands of cubic meters. The speed can range from very high to very high. Detached soil, stones and boulders can freely fall, bounce and roll. The rolling speed depends on the steepness of the slope. The trigger may be natural slope trimming such as streams and rivers, or weathering (e.g. freeze / thaw cycle), human activities such as excavation during construction and / or road maintenance, earthquake or strong earthquake. vibration, on traffic.

Landslide processes of this group in the Black Mountains are developed in deluvial, eluvial and alluvial-proluvial Quaternary sediments. They are found on slopes with a steepness of $8-10^{\circ}$ and higher, with a thickness of eluvial and deluvial covers of at least 1.5 $\mathrm{m}$. According to the mechanism, these are flow landslides - mudslides, landslides-flows. Their development is mainly associated with waterlogging of slopes as a result of abnormal precipitation. In the lower parts of the slopes, along the sides of erosional incisions, the activation of these processes is also caused by erosion [16].

\section{Conclusions}

Landslides are ubiquitous in the hills, mountains and high coasts that form land masses, and in many areas they cause significant human, social, economic and environmental damage and costs. Thus, reliable prediction of landslides and their consequences is of paramount importance. As with other natural hazards, landslide forecasting involves predicting "where" landslides can be expected (spatial forecasting), "when" or how often they can be expected (temporal forecast) and "how many", how large or destructive. it should be expected that landslides will be in the area (number, size, impact, forecast of destructiveness). The combined expectation of "where", "when" (or how often) and "how big" or destructive the landslide will be is called "landslide hazard". Unlike other natural hazards, two different types of forecasts are possible for landslides, namely: (i) forecasting individual landslides, i.e. predicting the behavior of one slope or part of it, and (ii) forecasting populations of landslides, i.e. forecasting the behavior of many (from tens to several tens of thousands) landslides occurring on the territory, and their spatial and temporal evolution [17].

For landslide processes in the mountainous part, there is a stable long-term tendency to an increase in the regional activity of their manifestation, due to an increase in the energy of the relief. As a result of the high values of the speeds of modern tectonic movements; in the Black Mountains, the activation of the landslide process during anomalous periods of a natural character will manifest (be realized) both in the development of existing forms (landslides and slopes) and in the emergence of new ones; at present, landslide processes are most widespread on the slopes of river valleys cutting through the Black Mountains, and in the future the slopes of the Argun, Sharo-Argun, Hulkhulau, Aksai, Yamansu river valleys will remain the most potentially dangerous in this respect; natural activation of landslide processes in the Black Mountains is caused by: a) an increase in the moisture content of the slopes; b) a decrease in their stability as a result of undermining during the activation of channel (vertical and lateral) erosion, which assumes the use of precipitation, temperature, and water content of rivers in forecasting as predictors [16]. 


\section{References}

1. V. V. Bardyuk., L. S. Stoyko, On the issue of an integrated assessment of the quality of surface waters (2020)

2. G. A. Bogdanovsky, Chemical Ecology (2018)

3. O. M. Mazur, Engineering Ecology, 315 (2020)

4. Ya. P. Molchanova, Hydrochemical indicators of the state of the environment (2019)

5. J. J. Andrea, C. Burns, J. Touza, Renewable Energy as a Luxury? A Qualitative Comparative Analysis of the Role of the Economy in the EU's Renewable Energy Transitions During the 'Double Crisis', Ecological Economics, 142, 81-90 (2020)

6. J. Yang, F. Zhang, X. Jiang, W. Sun, Strategic Flexibility, Green Management, and Firm Competitiveness in an Emerging Economy, Technological Forecasting and Social Change, 101, 347-356 (2018)

7. H. B. Dulal, R. Dulal, P. K. Yadav, Delivering Green Economy in Asia: The Role of Fiscal Instruments, Futures, 73, 61-77 (2019)

8. J. Mauritzen, Contractors and Scale: An Empirical Analysis of the California Solar Market (2020)

9. J. Meckling, L. Hughes, Protecting Solar: Global Supply Chains and Business Power, New Political Economy, 23(1), 88-104 (2020)

10. S. D. Belyaev, Using water quality targets in water management planning (2020)

11. A. M. Vladimirov, F. A. Imanov, Principles for assessing the ecological flow of rivers (2019)

12. F. Imanov, M. Ya. Asadov, Assessment of water resources and ecological state of the Samur River (2019)

13. A. N. Elizariev, T. B. Fashchevskaya, Assessment of water potential using GIS technologies (2018)

14. A. A. Daukaev, R. Kh. Dadashev, L. S. Gatsaeva, R. A. Gakaev, Landslides and mudflows in the Chechen Republic: synergetic aspects, 63 (2019)

15. R. A. Gakaev, I. A. Bayrakov, Geomorphological conditions of landslide formation in the Itum-Kalinskaya depression of the Chechen Republic (2018)

16. A. A. Daukaev, R. Kh. Dadashev, L. S. Gatsaeva, R. A. Gakaev, Landslides and mudflows in the Chechen Republic: synergetic aspects, 84-86 (2019) 